\title{
LA REGULACIÓN DE LA IMAGEN Y LA VOZ, DOS ASPECTOS JURÍDICOS RELEVANTES DE LA PERSONA HUMANA DENTRO DEL CÓDIGO CIVIL PERUANO Y SU ADAPTACIÓN A LOS TIEMPOS DEL COVID 19
}

THE REGULATION OF IMAGE AND VOICE, TWO RELEVANT LEGAL ASPECTS OF THE HUMAN PERSON WITHIN THE PERUVIAN CIVIL CODE IN THE TIME OF COVID 19

Emilio José Balarezo Reyes

* Maestro en Derecho de Abogado y Magister por la Universidad de San Martin de Porres, con estudios de Doctorado completo en la misma universidad y con un curso de Especialización en la Universidad de Salamanca España

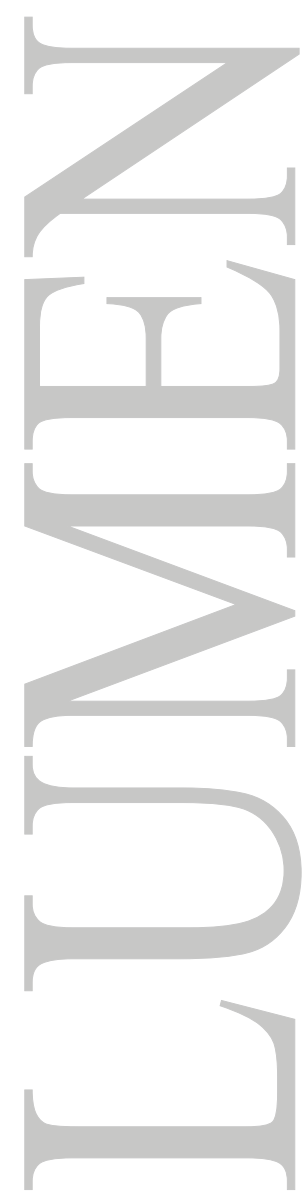




\title{
LA REGULACIÓN DE LA IMAGEN Y LA VOZ, DOS ASPECTOS JURÍDICOS RELEVANTES DE LA PERSONA HUMANA DENTRO DEL CÓDIGO CIVIL PERUANO Y SU ADAPTACIÓN A LOS TIEMPOS DEL COVID 19
}

\author{
THE REGULATION OF IMAGE AND VOICE, TWO RELEVANT LEGAL ASPECTS OF THE \\ HUMAN PERSON WITHIN THE PERUVIAN CIVIL CODE IN THE TIME OF COVID 19
}

Emilio José Balarezo Reyes

\begin{abstract}
RESUMEN
El estudio jurídico de la imagen y la voz se hace de necesario conocimiento de la sociedad, por lo que se lleva a cabo un análisis de todo el proceso evolutivo tanto histórico como jurídico en torno a la relevancia jurídica que tienen, desde la posición de la Constitución Política del Perú, el Código Civil de 1984 y el Código Procesal Civil, así como una examinación de la doctrina de nuestro país como en el derecho comparado. Se destaca su aplicación e interpretación en tiempos de pandemia como es la que actualmente vivimos con el COVID 19.
\end{abstract}

\section{PALABRAS CLAVES}

Imagen, Voz, Derecho, Código, Constitución, Intimidad, Protección, Persona, Regulación.

\begin{abstract}
The treatment that the Peruvian legal system has conferred on image and voice is an essential knowledge of society, for which reason an analysis of the entire evolutionary process, both historical and legal, is carried out regarding their legal relevance, from the point of view of the main national regulatory bodies such as the Political Constitution of Peru, the Civil Code of 1984 and the Civil Procedural Code, as well as an examination of national doctrine as a foreign one regarding its treatment in the field of national law and comparative law.
\end{abstract}

\section{KEY WORDS}

Image, Voice, Law, Code, Constitution, Privacy, Protection, Person, Regulation.

\section{INTRODUCCIÓN}

Dentro del desarrollo de las figuras que son inherentes al ser humano y constituyen la base de su distinción y reconocimiento dentro de la sociedad de la que forma parte, el papel que juegan la imagen como la voz, son desde nuestro punto de análisis relevantes ya que se encuentras unidas a la persona humana, ésta como ente de estudio encierra innumerables maneras y enfoques de ser estudiados y a lo largo del tiempo ha pasado por diferentes momentos adentrándose en instituciones que antes no se les daba el lugar ni la posición de relevancia que hoy tienen la imagen y la voz, ya que no solo es regulado por nuestro Código Civil sino que por su importancia también se les otorga un tratamiento en los derechos regulados en el Articulo $\mathrm{N}^{\circ} 2$ de la Constitución Política del Perú, de forma puntual en el inciso 7 , como lo veremos más adelante, estas dos figuras, la imagen y la voz tiene un tratamiento dual en los dos principales estamentos jurídicos de nuestro país, de allí radica su importancia como elementos inherentes a la persona.

Se podría decir que como elementos inmateriales inherentes a la persona han cobrado importancia jurídica, la legislación nacional no es ajena a ello, por ende se le da un tratamiento educido dentro del Primer Libro del Código Civil; de forma puntual el artículo 15 lo desarrolla de forma general ya que no nos da una definición de lo que debemos de entender por Imagen y Voz simplemente se limita a su uso así como los permisos respectivos para la utilización 
de ellos resaltándose una dualidad en el interés de los mismos ya sea de manera individual, colectiva como una primera óptica siendo la segunda desde la visión de lo privado y lo público.

De allí la importancia del estudio de este tema debido a la poca relevancia que le otorga muchas veces la sociedad sumado a su uso indiscriminado dado por los medios de comunicación, es necesario establecer con claridad los limites como los permisos respectivos para la utilización y aprovechamiento y nuestro Código Civil se ha inclinado por ese camino como lo veremos más adelante, pero pensamos que el estudio de ambas figuras debe de ir más allá que solo el Código Sustantivo, sino que la importancia normativa necesariamente tiene que estar acompañada con la regulación que en las diferentes etapas de la historia se le ha otorgado partiendo desde un enfoque general aterrizando en uno netamente jurídico.

Como bien lo refiere el profesor Morales Godo ${ }^{1}$ al expresar en torno a este tema lo siguiente: "Nuestro sistema jurídico establece el derecho a la imagen y voz como derechos autónomos, diferenciándolos del derecho a la intimidad, aun cuando un mismo acto pudiera violentar simultáneamente estos tres derechos, como sería la captación a través de un video con voz, un acto íntimo" (Morales, 2009, p.278)

Por su parte la profesora Alcántara ${ }^{2}$ manifiesta en torno al tratamiento peruano los siguientes puntos: "Los derechos a la imagen y a la voz protegidos por la presente norma, forman parte de la esfera de los denominados "Derechos de la Personalidad" cuyo reconocimiento constitucional, en la mayor parte de países del mundo, ha propiciado la regulación en los códigos civiles y/o en leyes especiales" (Alcántara, 2007, p.128)

\section{2.-Tratamiento Jurídico -Evolutivo de la Imagen. 2.1.-Antecedentes.}

En Roma, era una distinción reservada a los nobles el uso del ius imaginis, que permitía formar una máscara de cera a los cadáveres de éstos para disfrutar del privilegio de su exposición en los atrios de las casas y en los cortejos fúnebres.

Con el transcurrir del tiempo hasta la Edad Contemporánea, la pintura y la escultura permitieron perpetuar en lienzos, bronces y mármoles, con expresión depurada, los rostros, gestos y expresiones de muchos personales en este caso había que posar para el artista, por lo que no se concebía las reproducciones tal y como hoy las conocemos.

La inquietud que impulsó el reconocimiento de este derecho nace con el invento de la fotografía en 1829 por el químico francés Nicéforo Niepse. El invento fue perfeccionado posteriormente por el artista Luis Jacobo Mandé Daguerre, creador del Daguerrotipo el 14 de agosto de 1839.

En 1841, William Henry Fox Talbot en Francia presenta el negativo. Por su parte, M. Blamquart- Enrard introduce la reproducción de la fotografía sobre el papel y Dubroni crea las primeras cámaras portátiles siendo el aporte de George Eastman inventa el uso de rollos de papel emulsionado.

En 1891 Gabriel Lippman obtiene las primeras imágenes a color, con lo que obtiene el Premio Nóbel de Física, pero es con la cinematografía nacida en 1895 en que se daría acceso a la toma de imágenes vivas, móviles, no estáticas.

Morales, J. (2009) Instituciones del Derecho Civil. Lima: Palestra Editores.

Alcántara, O. (2017) Comentario al Artículo 15 del Código Civil en Código Civil Comentado. Tomo I. Lima: Gaceta Jurídica. 
No podemos dejar de mencionar el tratamiento que se le ha otorgado a la imagen a través del tiempo en lo que se refiere a su tratamiento sustancial el profesor Fernández Sessarego ${ }^{3}$ establece lo siguiente "En cuanto al derecho a la propia imagen cabe señalar que se trata de uno de los derechos de la persona que ha sido profusamente estudiado y desarrollado por la doctrina y protegido desde hace varias década por la jurisprudencia comparada" (Fernández, 2009, p.434)

\section{2.-Concepción Jurídica de Imagen.}

La primera concepción jurídica consideró a la imagen como una manifestación del cuerpo; luego, de la misma manera que la persona tiene derecho sobre su cuerpo, debe tenerlo sobre su imagen, la cual es su fiel reproducción, algo así como la sombra, partiendo de un concepto vinculante entre el cuerpo y el reflejo que emana del mismo ante la luz, este primer alcance de un concepto pragmático de lo que es la imagen nos lleva a determinar que siempre fue un tema relevante

Es interesante el aporte de Keyssner, el cual citado por Azumendi ${ }^{4}$ sostuvo la ilicitud de la simple apropiación y, por supuesto, también de la publicidad: "El fotografiado, en defensa de su cuerpo, puede arrebatar la máquina del fotógrafo y estrellarla para evitar la impresión de la placa, como un modo de ejercer la legítima defensa" (Azurmendi, 1998, p.63)

Este concepto como se puede apreciar permite el uso de la fuerza como instrumento de protección de un derecho, es un inicio de la defensa de este derecho un poco pragmático pero es el punto de comienzo de su regulación y respaldo por el derecho.

Dos ejemplos de este tipo de situación los podemos encontrar en la afamada película "EI Padrino" de Francis Ford Coppola de 1972, ambas se desarrollan durante el matrimonio de la hija de Don Vitto, la primera cuando uno de los capos de la mafia Emilio Barzini, es retratado sin su consentimiento ordenando a su seguridad que arrebaten la cámara al periodista y luego destruye con sus manos el negativo, y la segunda cuando el hijo mayor Sonny Corlone, expulsa a los periodistas que ingresan sin autorización a la boda de su hermana destruyendo las cámaras y los negativos de las imágenes captadas por los periodista.

El primer reconocimiento legislativo lo da la ley alemana del 10 de Noviembre 1842; luego la rusa del 21 de Febrero de 1845; la inglesa del 29 de Julio 1862; la húngara de 26 de Abril de 1884, la belga 22 de Mayo de 1886; la colombiana de 26 de Octubre de 1886; la ecuatoriana de 03 de Agosto de 1887; la suiza del 23 de Abri1de 1888 y la del Estado de California de 1899.

En el caso peruano, se encuentra regulado en la Constitución de 1993 en el Artículo 2 de forma específica en el inciso 7 que expresa:

“Toda persona tiene derecho: (...)

7. Al honor y a la buena reputación, a la intimidad personal y familiar así como a la voz y a la imagen propias. Toda persona afectada por afirmaciones inexactas o agraviada en cualquier medio de comunicación social tiene derecho a que éste se rectifique en forma gratuita, inmediata y proporcional, sin perjuicio de las responsabilidades de ley"

El citado artículo dentro de la carta magna reconoce la relevancia de las figuras del honor, la buena reputación, la intimidad personal y familiar, como también les otorga la importancia que merece tanto a la voz como a la imagen, estos últimos como aspectos inherentes al ser

Fernández Sessarego, C.(2009) Los 25 años del Código Civil Peruano de 1984.Lima: Motivensa

Azurmendi, A (1998) El Derecho a la Propia Imagen. Su identidad y aproximación al Derecho a la Información. Madrid: Editorial CIVITAS S.A. 
humano en lo que refiere a su proyección dentro de la sociedad de la que forma parte tienen un reconocimiento constitucional debido a que la trascendencia que tiene se sostiene en que forma parte del ser humano, en su propia naturaleza, como lo observamos ambos se encuentran indesligables siempre se les da a estos dos elementos (imagen y la voz) un tratamiento conjunto en su reconocimiento jurídico que se les ha otorgado.

Al respecto el profesor Rubio ${ }^{5}$ expresa lo siguiente: "El derecho a la propia voz consiste en que solo uno puede utilizar su voz y que nadie más puede hacerlo sin autorización. La voz de una persona le pertenece e identifica. En realidad, forma parte de su ser, como su rostro, su cuerpo y su manera de pensar. El derecho a la propia imagen es el uso que tiene toda persona de su propio cuerpo, sus imágenes y reproducciones, así como la prohibición de que otro las utilice sin su consentimiento..." (Rubio, 2008, p.29)

Por su parte Chaname ${ }^{6}$ indica respecto a este inciso lo siguiente: "El denominado derecho a la imagen se regula como manifestación de los derechos de la personalidad, junto con el derecho al honor y el derecho a la intimidad, implican la existencia de un ámbito propio y reservado frente a la acción y conocimiento de los demás, necesario para mantener una calidad mínima de la vida humana, son derechos que forman parte de los bienes de la personalidad que pertenecen al ámbito de la vida privada" (Chaname, 2009, p.130)

Por último, García Toma ${ }^{7}$ en lo que respecta a los temas referidos expone lo siguiente: "la voz, es el conjunto de sonidos que permite la emisión, por el hombre, de expresiones orales, canticos, silbidos o gritos. Al considerarla digna de protección, se asume que la voz de una persona le pertenece e incluso la identifica. Nuestra constitución señala que la voz integra la persona; por ende, nadie puede grabarla ni utilizarla sin su autorización. Este derecho tiene singular importancia en el caso de los cantantes, narradores, declamadores, etc.

El derecho a la propia imagen, consiste en la facultad que cada persona tiene para autorizar o prohibir que su figura sea reproducida con fines lucrativos o sin ellos. Es evidente que la imagen se constituye a partir de la expresión corporal y de su posterior representación. Ello deviene en una manifestación del ser humano respecto a la cual se le otorga un derecho particular y concreto en favor de la defensa de su personalidad..." (García, 1998, p. 89)

En el derecho comparado, de manera precisa en Brasil, el Derecho a la Imagen está previsto como derecho fundamental a si en palabras del profesor Nery ${ }^{8}$ respecto a este tema indica lo siguiente: "Una primera visión que les quería mostrar era el derecho de imagen dentro del sistema brasileño como derecho fundamental. Como protección expresa en la constitución brasileña. Este derecho de imagen tiene que ser combinado con aquello que determina el Código Civil Brasileño que entro en vigor en Enero de 2003" (Nery, 2019, p.48)

Por su parte Mesinas ${ }^{9}$ citando jurisprudencia del Tribunal expresa: "El derecho a la imagen protege, básicamente, la imagen del ser humano, ínsita en la dignidad de la que se encuentra investido, garantizando el ámbito de la libertad de una persona respecto de sus atributos más característicos, propios e inmediatos, como son la imagen física, la voz o el nombre, cualidades definitorias, inherentes e irreductibles de toda persona (Exp. Nº446-2002-AA, Tribunal Constitucional)"

5 Rubio, M. (2008) Para Leer la Constitución de 1993. Lima: Fondo Editorial de la Pontificia Universidad Católica del Perú.

6 Chaname, R. (2009) Comentarios a la Constitución. Lima: Jurista Editores.

7 García V. (1998) Análisis Sistemático de la Constitución Peruana de 1993. Tomo I. Lima: Fondo de Desarrollo Editorial de la Universidad de Lima.

8 Nery, N. (2019) Cesión de Derechos de Imagen en Congreso Internacional de Derecho Civil. Tomo I. Lima: Instituto Pacifico - Universidad de Lima.

9 Mesinas, F. (2010) Jurisprudencia civil y procesal civil de carácter constitucional. Lima: Gaceta Jurídica. 


\section{3.-El derecho a la imagen comprende los siguientes aspectos:}

A) Captación u obtención de la misma, podríamos definirla como la etapa inicial de este proceso dinámico en torno a la imagen, la cual con este primer paso nos señala la manera o la forma de como se ha conseguido muchas veces con criterios jurídicos distintos de acuerdo al país como a la sociedad donde se va aplicar la misma, como las practicas que se incurren en la obtención de la imagen pudiendo ser permitidas como prohibidas es aquí donde tienen que entrar a tallar el derecho como elemento diferenciador, ubicándose como un filtro regulatorio en lo que respecta a la viabilidad de la obtención de la imagen, delineando los momentos, lugares y situaciones permisibles en los que se pueden plasmar.

B) Reproducción, esta segunda parte de la dinámica en torno a la imagen se sostiene en la multiplicación de la imagen obtenida, de acuerdo al medio utilizado para ello, pudiendo ser el inmaterial como es el caso de las imágenes digitales como el físico a través de la impresión a través del papel como o de los paneles publicitarios, afiches, etc.; de esta manera el ámbito de llegada como de uso de la imagen se extiende de manera importante, aumentando las posibilidades de su conocimiento por la población, es decir la sociedad tendrá latente la posibilidad de conocer la imagen en las diversas formas en que ha sido replicado.

C) Publicación, esta última etapa por la que atraviesa el desarrollo del derecho de la imagen, destacando a esta como elemento dinámico nos expresa la manera en que se da la concretización de la figura de la imagen a través de los diferentes medios de difusión que permiten la divulgación de la misma pudiendo ser llevado a cabo con o sin consentimiento afectando o no derechos, es por ello que el uso de la imagen, por parte sobretodo de los medios de comunicación sean estos escritos, audiovisuales como digitales en los últimos tiempos han tenido inconvenientes en el uso inapropiado de las imágenes al no contar con los permisos y autorizaciones respectivas.

En este mismo sentido el profesor Guevara $^{10}$ coincide en señalar los tres aspectos antes indicados: "El derecho a la imagen comprende los siguientes los siguientes aspectos: 1) captación u obtención de la misma; 2) reproducción; y, 3) publicación. El titular ejerce tal derecho sobre todos esos aspectos. Quienes reciban consentimiento para el uso de la imagen podrán emplearlo solo sobre el aspecto o aspectos que los hubiera autorizado" (Guevara, 2004, p.167)

El lado positivo del derecho reside en la facultad del titular de obtener, reproducir y publicar la imagen; el lado negativo, en la de excluir la obtención, reproducción y publicación de la imagen por quien carece de dicha autorización.

El consentimiento por el uso de la imagen puede darse limitada en el tiempo o espacio; como también en exclusividad.

El rostro del hombre está determinado por su relación inmediata con un sujeto individual, que es único y que tiene constancia de serlo en el sentido de irrepetible, de distinto a los demás.

La imagen no es un signo más en el proceso comunicativo humano, la imagen del hombre es una encarnación, una plasmación, de los rasgos esenciales de la personalidad y en consecuencia, la imagen participa de la dignidad personal propia del ser humano. Aquí radica el carácter valioso de la imagen y de su adecuada protección.

10 Guevara. V (2004) Personas Naturales. Lima: Gaceta Jurídica. 
La imagen en su dimensión personal se caracteriza por la referencia inmediata a la persona individualizada; en su dimensión relacional, por estar necesariamente integrada a un proceso de comunicación.

\section{3.-Tratamiento Jurídico - Evolutivo de la Voz. 3.1.-Antecedentes.}

Concepto del Diccionario de la Real Academia Española expresa lo siguiente: "Sonido que el aire expelido de los pulmones produce al salir de la laringe, haciendo que vibren las cuerdas vocales"

La voz merece un tratamiento y protección jurídica autónoma y que se traduce en el derecho que tiene el titular de disponer de la misma, permitir su reproducción, gratuito u oneroso. Y constituye un instrumento fundamental para muchas personas constituyéndose en pieza elemental de su trabajo como es el caso de los cantantes, oradores, locutores, etc.

Respecto al tema de la voz, el profesor Fernández Sessarego ${ }^{11}$ señala lo siguiente: "Merece mención especial la novedad que representa a nivel de la codificación comparada, la incorporación dentro del texto de un Código Civil, del derecho a la voz. El Código Civil peruano es uno de los escasos códigos civiles que tutela la voz. En cualquier caso, es el primero en el área latinoamericana que lo incluye entre los derechos de la persona al lado del derecho a la imagen" (Fernández, 2009, p.433)

En ese mismo sentido es importante la apreciación del profesor italiano Rescigno ${ }^{12}$ cuando señala lo siguiente:

La ampliación del catálogo de los derechos de la personalidad - que comprende también el derecho a la voz que se sitúa entre las más recientes adquisiciones de la doctrina y practicase resuelve, en definitiva, con el carácter abierto y flexible de una categoría que se dirige a la defensa de valores que van desde la vida hasta la intimidad privada (Rescigno, 1986, p.242)

Por lo que su tratamiento jurídico no pasa desapercibido si bien en sus inicios recibió un tratamiento indiferente que con el transcurrir del tiempo se le ha venido dando un reconocimiento paulatino hasta considerarlo un derecho que tiene la persona y que vulnera su intimidad así Guevara $^{13}$ nos señala lo siguiente: "Más específicos fueron los juristas que asistieron a la Conferencia de Juristas Nórdicos de 1967, en la tarea de establecer la nómina de acciones que más comúnmente se usan para atacar el derecho a la intimidad. Tales son para ellos los siguientes:

6) la captación de los mensajes telefónicos o telegráficos.

8) la grabación sonora y las tomas de fotografías o películas" (Guevara, 2018, p.66)

En opinión del profesor Valencia Zea ${ }^{14}$ el derecho a la voz se manifiesta en todas las direcciones posibles:

Fernández Sessarego, C. (2009) Op. Cit.

2 Rescigno, P.(1986) Comentarios al Libro de Derecho de las Personas del Nuevo Código Civil Peruano de 1984 en El Código Civil Peruano y el Sistema Jurídico Latinoamericano. Lima: Cultural Cuzco.

13 Guevara. V (2018) El Derecho a la Información frente al Derecho a la Intimidad. Lima: Universidad Femenina del Sagrado Corazón.

14 Valencia Zea, A y Álvaro Ortiz (2008) Derecho Civil. Tomo I. Parte General y Personas. Bogotá: Temis. 
"1.- La voz de los cantantes, son utilizadas a través de ediciones fonográficas con fines de reproducción, difusión o ventas

2.- La voz de los oradores, recitadores y expositores, la cual no puede ser reproducidas sin asentimiento del titular o de sus familiares, si ha muerto

3.- La voz frente a conversaciones privadas, frente a lo cual rige lo mismo que para el caso anterior" (Valencia, 2008, p.566)

Como lo manifiesta el profesor colombiano estas tres maneras en las cuales se pueden ver plasmadas las diferentes situaciones en que se concretiza la voz como instrumento principal para determinadas personas ya que se constituye en el eje de su profesión es decir sin su presencia no se podría concretizar su actividad, en primer lugar los cantantes basan su actividad en su voz, la cual al ser su herramienta de trabajo la protegen y cuidan, a través de la misma le va a permitir a todos los que se dedican a esta profesión, realizar tanto presentaciones como concretizar producciones que también han pasado por un proceso debido a la tecnología desde los discos de vinilo, los CDs llegando a la música digital que de manera gratuita o pagada hoy se ofrecen.

La elocución que lleva a cabo un expositor o catedrático, el uso que se da del mismo como las consecuencias que se derivan de esta actividad, donde se expresan opiniones o que concitan la atención especializada debido a los conceptos como los conocimientos que se plasman a través del mismo, se ve semejanza con la regulación peruana como lo vamos apreciar más adelante en lo que respecta a la protección de los mismos en el caso de la intervención de los familiares en caso de haberse producido el deceso del locutor.

Por último, se vincula el tema de la privacidad con la voz en la medida que la misma es utilizada como vía para el desarrollo de conversaciones que solo y únicamente implican y competen a la persona que emite la voz y la persona o personas que recepcionan el mensaje de esta manera encontramos una conexión sumamente relevante entre la intimidad y las comunicaciones que tienen como principal elemento a través del cual se transmiten como es el tema de la voz.

Por su parte Varsi ${ }^{15}$ en lo que respecta a la voz manifiesta su punto de vista de la siguiente manera:

"El derecho a la voz es la protección que se brinda a la sonoridad de la persona, a la forma que esta tiene de comunicarse sea a través de un lenguaje vocal o de otro sonido expresivo de forma que nadie pueda hacer uso total o parcial de ella sino mediante autorización del titular" (Varsi, 2014, p.589)

Es interesante señalar la definición del profesor Espinoza ${ }^{16}$ en la manera cómo define el derecho sobre la propia voz: "El derecho a la voz es la situación jurídica en la que se tutela el sonido de las cuerdas vocales de la persona, a efectos que su reproducción se haga de manera fiel y con el consentimiento de la misma. Este derecho también forma parte del derecho a la identidad entendido en su manera estática" (Espinoza, 2014, p. 512)

\section{4.- La Imagen y la Voz en el Libro I de Derecho de Personas.}

Podemos expresar que el tratamiento que tiene la imagen como la voz, en su reconocimiento de ser figuras jurídicas está en el artículo 10 del Código Civil Italiano de 1942, desarrollando para

15 Varsi, E. (2014) Tratado de Derecho de las Personas. Lima: Gaceta Jurídica.

16 Espinoza, J. (2014) Derecho de las Personas. Concebido -Personas Naturales. Lima: Editorial Rhodas. 
el caso peruano determinadas variantes, tal y como lo señala el maestro Fernández Sessarego ${ }^{17}$ al apuntar lo siguiente: "En lo concerniente al derecho sobre la imagen, el artículo 15 del Código Civil Peruano se inspira tanto en la doctrina como en el artículo 10 del Código Civil Italiano, aunque el articulo 15 incorpora también el derecho a la voz. Sobre el particular cabe señalar que, atendiendo a la crítica efectuada por un sector de la doctrina italiana, en especial por De Cupis, el codificador evita cometer el error de confundir la tutela de la imagen con la del honor" (Fernández, 1990, p.126)

Al respecto es importante el aporte de Max Arias $^{18}$ el cual indica lo siguiente en lo referente al tratamiento del Derechos inherentes a la persona dentro del Libro I: "Entre las otras novedades que trae el libro sobre Derecho de las Personas están las normas en virtud de las cuales ...se da la reiteración del principio de privacidad por cuya virtud la imagen y la voz de una persona no pueden ser aprovechadas sin la autorización de ella y si ha muerto sin el asentimiento de su cónyuge, descendientes, ascendientes o hermanos excluyentemente y ese orden" (Arias, 1991, p.52)

\section{5.-El Tratamiento de la Imagen y la Voz dentro del Código Civil Peruano de 1984. Derecho a la imagen y voz}

Artículo $15^{\circ}$.- La imagen y la voz de una persona no pueden ser aprovechadas sin autorización expresa de ella o, si ha muerto, sin el asentimiento de su cónyuge, descendientes, ascendientes o hermanos, excluyentemente $y$ en este orden. Dicho asentimiento no es necesario cuando la utilización de la imagen y la voz se justifique por la notoriedad de la persona, por el cargo que desempeñe, por hechos de importancia o interés público o por motivos de índole científica, didáctica o cultural y siempre que se relacione con hechos o ceremonias de interés general que se celebren en público. No rigen estas excepciones cuando la utilización de la imagen o la voz atente contra el honor, el decoro o la reputación de la persona a quien corresponden.

El presente artículo constituye una innovación en la regulación de un tema tan sensible como la imagen y la voz dentro del Código Civil en el ámbito peruano, el Código de 1936 no lo regulaba, como lo manifiesta el maestro Fernández Sessarego ${ }^{19}$ cuando señala: "En cuanto al derecho sobre la propia imagen debe ponerse de manifiesto su carácter predominantemente privado, por lo que resulta indiscutible que encuentre su sede natural en el Derecho Civil" (Fernández, 1984, p.25)

Se puede constatar de manera directa la tendencia innovadora de parte del Código Civil de 1984 al incorporar determinados derechos que pasaban en desapercibidos, pero que encierran aspectos inherentes al ser humano muchas veces que estaban dejados de lado y no se les otorgaba el debido tratamiento jurídico resaltando que forman de manera intrínseca la proyección del hombre sobre la sociedad.

Es importante señalar la opinión del profesor Morales $^{20}$ al referirse a este articulo expresa: "Nuestra legislación, a través del artículo 15 del Código Civil de 1984, reconoce el derecho a la imagen y a la voz, requiriéndose de consentimiento de la persona para el aprovechamiento de la imagen y voz, estableciéndose, así mismo, que no se requiere de consentimiento para la divulgación, cuando se trata de la imagen de un personaje público captada en una actuación pública, salvo que esta utilización atente contra el honor, el decoro o la reputación de la persona" (Morales, 2009, p.279)

\footnotetext{
17 Fernández Sesarego, C. (1990) Nuevas Tendencias en el Derecho de las Personas. Lima: Fondo Editorial de la Universidad de Lima.

18 Arias Schreiber. Max (1991) Luces y Sombras del Código Civil. Tomo I. Lima: Studium.

19 Fernández Sessarego, Carlos (1984) La Persona en la Doctrina Jurídica Contemporánea. Lima: Fondo Editorial de la Universidad de Lima.

20 Morales, J. (2009) Op. Cit.
} 
Es de destacar que el planteamiento que esboza el artículo nos ofrece dos partes bien marcadas en lo que refiere en primer lugar al aprovechamiento de la imagen de una persona partiendo de dos posibilidades puntuales que este viva y ejerza de manera directa los derechos que le corresponden como también una vez fallecido la titularidad de la defensa de sus derechos le serán asignados a sus familiares siguiendo el orden de prelación respectivo.

Por otra parte en desarrollo del citado artículo se destaca el tratamiento que se le da a la característica de la notoriedad de la persona siendo esta situación recaída por el rol social que esta cumple, dentro del estado pudiendo ser esta de carácter cultural, académica, científica, desarrollando de esta forma las actividades o acontecimientos donde no es necesario permiso alguno, debido al grado de necesidad en el interés social que se tiene en torno a la persona, siempre y así lo resalta el artículo que estas actividades se desarrollen en público, termina la redacción señalándose las prohibiciones en el uso de la imagen cuando las mismas vayan en contra del honor, el decoro y por último la reputación de la persona de quien se obtiene.

Podemos expresar que el artículo tiene por finalidad resaltar la protección que otorga el derecho nacional a estos derechos, instituciones vinculadas a la esfera de la intimidad. La imagen no puede ser publicada, expuesta o utilizada, lo mismo que la voz, es decir tienen un tratamiento equivalente, ya que exigen de esa manera el consentimiento del titular y si ha muerto de sus herederos. El principio general recogido por este artículo permite de acuerdo a lo expresado en el texto, la simple captación de la imagen de las personas en tanto esta no se exhiba en público o se utilice para fines no autorizados.

En palabras del profesor Fernández Sessarego ${ }^{21}$, a justificación del artículo 15 se sostiene en lo siguiente: "El numeral tiene como objetivo la protección jurídica de la imagen y la voz, consideradas como aspectos vinculados a la esfera de la intimidad de la persona. Es así que la norma en mención establece, como regla general que la imagen y la voz no pueden ser aprovechadas, es decir publicadas, expuestas o utilizadas sin el asentimiento de la persona" (Fernández, 2000, p.65)

La relevancia del aprovechamiento debe de ser analizado de forma detallada, es decir sacar ventaja de un aspecto tan inherente al hombre no puede estar concatenado a un perjuicio o resultados negativos de manera directa sobre el de forma individual como de su familia en el plano colectivo de allí la viabilidad de los permisos que tiene que obtenerse con la finalidad de obtener la utilización de estas figuras propias del ser humano.

Lo que se desea es encontrar en la imagen, la voz y demás componentes que desarrolla el articulo componentes que se convierten en signos distintivos es decir que permitan individualizar como reconocer a una determinada persona hacerla distinta de las demás con las que conjuntamente conforma lo que es la sociedad.

En lo que respecta a esta posición el profesor Marcial Rubio 22 expresa: "La voz no requiere mayor descripción. La imagen es el aspecto físico de la persona, o la representación de él. Nótese que no es solo el aspecto físico sino cualquier reelaboración o representación a través de las cuales la persona pueda ser identificada" (Rubio, 1992, p.89)

Si bien encontramos, la concurrencia de varios derechos como son el de la imagen, el honor, la voz, etc.: habría que señalar que cada uno de ellos tiene sus propias características y además que por estar integrados en un mismo artículo no quiere decir que sean iguales ni que uno tenga

21 Fernández Sessarego, Carlos (2000) Derecho de las Personas. Lima: GRIJLEY.

22 Rubio. M. (1992) El Ser Humano como Persona Natural. Biblioteca para Leer el Código Civil. Vol.XII. Lima: Fondo Editorial de la Pontificia Universidad Católica del Perú. 
más importancia que otro. En lo que respecta a este punto concordamos con lo expuesto por el profesor $\mathrm{Cieza}^{23}$ que plantea lo siguiente: "Concordamos con esta visión de la autonomía del derecho a la imagen frente al derecho subjetivo a la intimidad y al honor o reputación, pues la utilización de la imagen de una persona para fines que no sean de interés público y con fines comerciales requiere el asentimiento y la anuencia del sujeto" (Cieza, 2016, p.106)

La violación de los derechos de la imagen y a la voz puede acarrear diversas consecuencias jurídicas las que tienen que ser debidamente demostradas y analizadas por la judicatura al momento de sentar una posición al respecto. La doctrina extranjera al analizar la regulación que le otorga el artículo 15 del Código Civil Peruano también se ha manifestado, en torno a su relevancia así Ameal ${ }^{24}$ expresa lo siguiente: "En razón de lo expuesto y retornando al tema de la protección al derecho a la imagen entiendo que todo daño que la violación provoque debe ser reparado, tratase de un daño material o de cualquier otra especie..." (Ameal, 2010, p. 693)

\section{6.-La interpretación y aplicación de la Imagen y la Voz en tiempos del COVID 19.}

La presencia de la Pandemia ha traído consigo que se presenten un sinnúmero de posibilidades para llevar a cabo una aplicación como una interpretación de las diversas figuras jurídicas existentes dentro del ordenamiento jurídico de forma general y del ámbito civil de forma particular, esta situación no es ajena a las figuras del voz y de la imagen ya que por las circunstancias que vivimos tanto las comunicaciones como la información han recurrido al uso de las mismas con diversos objetivos y entre ellos se ha podido ver la exposición de las personas que por su rol dentro del Estado han tenido un rol sumamente relevante e importante, como también la utilización de medios masivos como la radio y el uso de medios virtuales para el dictado de clases y formas de conexión entre las personas, lo cual ha podido contraer consecuencias como resultados donde el Derecho Civil tiene que ser una herramienta de aplicación adecuada y pertinente.

Para proceder al análisis nos vamos a sostener en las diferentes situaciones que a diario palpamos en la realidad en donde se concretizan estas instituciones en tiempos actuales de Pandemia por el COVID 19 que vivimos:

- En el uso de la imagen que a diario se utiliza a través de los diferentes medios de comunicación de los funcionarios públicos que trabajan en el Estado que con la finalidad de llevar a cabo declaraciones en lo que respecta a la forma en que se está diseñando la estrategia por parte del gobierno para combatir el COVID 19 en nuestro país así por ejemplo: las declaraciones que realiza el Presidente cuyas imágenes aparecen a través de la televisión o de los periódicos digitales con el objetivo de mantener informada a la población.

- El uso de la imagen de los ministros, en sus diversas modalidades, televisión, redes sociales, canales virtuales, etc.; en especial de aquellos que por la coyuntura necesariamente por su conexión con las decisiones del Gobierno por ejemplo la imagen del Ministro de Salud entregando un lote de medicinas para la atención del COVID 19 en un determinado hospital de la capital.

- En el caso de un destacado deportista por ejemplo el de la fondista nacional Inés Melchor utilizan su imagen para una campaña de concientización de la población para que tome las medidas de higiene respectivas y así prevenir la propagación de la pandemia en nuestro país.

- El uso de la imagen del Decano del Colegio Médico en una conferencia de prensa exhortando a la población al uso de las mascarillas en cada una de sus salidas a la calle con el objetivo 
de que se protejan de la pandemia y de esa manera poder reducir de manera ostensible el número de infectados, para poder llegar a una cifra controlable y de esa forma llevar a cabo los controles e indicaciones en los centros de salud.

- La utilización de la imagen de actores y actrices conocidos en las clases escolares con el objetivo de llevar a cabo un acercamiento con la población, a través de instrucción en valores que son transmitidos a la sociedad.

- En el caso de las declaraciones de la Ministra de Economía a una radio local en la cual informa de las medidas adoptadas por el gobierno en el otorgamiento de los bonos respectivos con la finalidad de ayudar a las familias más necesitadas durante el desarrollo de la pandemia, explicando cada uno de los pasos a seguir para el cobro respectivo en las entidades financiera.

- Otro punto donde también podemos ver plasmado el ejercicio de la defensa como del tratamiento jurídico de la voz, es cuando se toman declaraciones por medio de las grabadoras a los pacientes hospitalizados los cuales comienzan a denunciar la verdadera realidad en la que se encuentra la salud, la cual desea ser ocultada por el Gobierno.

- Un caso interesante podría plantearse cuando una persona dedicada a la labor científica con la finalidad de contribuir a la investigación en pro de la cura para el COVID 19, relata mediante una grabadora cada una de las etapas por las cuales ha pasado en el desarrollo de la enfermedad. En el caso del fallecimiento de esta persona, la divulgación de estas grabaciones deberían de darse con el consentimiento de los familiares, de acuerdo al orden que estipula el Código Civil.

- La utilización de vehículos que transmiten a través de parlantes mensajes e indicaciones por parte de diferentes galenos que conlleven de manera apropiada el cuidado que la población debe de cumplir en el denominado aislamiento social con el objetivo con la finalidad de llevar a cabo una concientización por parte de la población.

- La grabación de mensajes orales de cuidado y protección e higiene en idioma original para la población de las comunidades como de los pueblos alejados de la ciudad y evitar la propagación de la enfermedad.

\section{7.- EI Aspecto Procesal referente a la protección de la Imagen y la Voz.}

El Código Procesal Civil de 1993, lleva a cabo un tratamiento procesal al tema referido a estos derechos, es así que el artículo 686 expresamente lo siguiente:

\section{Articulo 686}

Cuando la demanda pretenda el reconocimiento o restablecimiento del derecho a la intimidad de la vida personal o familiar, así como la preservación y debido aprovechamiento de la imagen o la voz de una persona, puede el Juez dictar la medida que exija la naturaleza y circunstancias de la situación presentada.

Del análisis de la norma adjetiva resalta una situación interesante como es la búsqueda del reconocimiento o recuperación de un derecho que no ha sido valorado o protegido en un primer momento con el objetivo de otorgarle el respaldo del ordenamiento jurídico, el acercamiento al citado artículo establece una protección a la figura de la intimidad, como derecho clave que es inherente al ser humano respecto a ese blindaje jurídico que se le debe de otorgar a ese aspecto interno, propio y reservado y exclusivo del hombre.

Prosigue el artículo desarrollando una protección conjunta a la imagen y a la voz, desde dos ángulos sumamente claros como es de mantenerlos en un estatus de protección permanente es decir que no se realice ningún acto que vaya en contra de ellos, por otro lado se coloca en la posición del debido aprovechamiento, es decir se lleva a cabo un análisis de la forma en que se 
ha estado utilizando si se encuentra luego de una evaluación realizada por el Juez que amerite su intervención. Culmina el artículo, expresando la materialización de las facultades que tiene el Juez de administrar justicia, gracias a ese razonamiento le permite en su facultad discrecional que pueda utilizar de acuerdo a las características del caso que se le presente en su despacho, como por ejemplo una figura procesal que tenga el objetivo de impedir la propagación en los medios o instrumentos con los cuales se afecte o vulnere la intimidad como también la imagen o la voz de las personas afectadas que forman parte del proceso.

\section{8.-Conclusiones.}

- El tratamiento de la imagen como la voz, como instituciones con relevancia jurídica han pasado por un proceso evolutivo, que va de un tratamiento muy empírico a otro especializado producto del reconocimiento paulatino de los derechos que la persona humana tiene dentro de una determinada sociedad.

- El reconocimiento que se le otorga a estos derechos en el Perú través del Código Civil y en la Constitución nos indica que son elementos importantes dentro del proceso de individualización del ser humano, ya que tienen un contexto jurídico que los reconoce y protege.

- La jurisprudencia en los últimos años ha llevado paulatinamente en sus diferentes pronunciamientos un reconocimiento de la importancia como el papel que juegan tanto la imagen como la voz.

- La imagen como la voz al ser derechos personalísimos inherentes a la persona tienen un enfoque y tratamiento conjunto dentro de los derechos de la persona, están íntimamente vinculados a la intimidad, a la reserva personal, etc.

- El uso de la tecnología como los demás adelantos virtuales usados por la sociedad en el mundo de hoy hacen que la obtención tanto de la imagen como la voz y los permisos para sus usos se conviertan en situaciones de análisis mucho más delicadas de analizar en lo referente a los resultados que se puedan obtener de los mismos.

- A la fecha la importancia que tiene la imagen como la voz obliga a un replanteamiento en lo que respecta tanto a su uso como a su protección por parte del derecho ya que a diario son objeto de grandes negociaciones y firma de contratos donde se ponen en juego importantes sumas de dinero.

- En situaciones sumamente especiales y delicadas como es la que se está atravesando actualmente el defensa y protección de la imagen y la voz ya que deben recibir la protección adecuada, y no deben de caer en una desnaturalización que hagan perder su verdadera sentido como derechos inherentes a la persona.

\section{9.-Bibliografía.}

- Alcántara, O. (2017) Comentario al Artículo 15 del Código Civil en Código Civil Comentado. Tomo I. Lima: Gaceta Jurídica.

- Ameal, O. (2010) Proyección Integral a la Propia Imagen en La Responsabilidad Civil y la Persona en el Siglo XXI. Libro Homenaje a Carlos Fernández Sessarego. Lima: IDEMSA.

- Arias Schreiber, M. (1991) Luces y Sombres del Código Civil. Lima: Studium.

- Azurmendi, A (1998) El Derecho a la Propia Imagen. Su identidad y aproximación al Derecho a la Información. Madrid: Editorial CIVITAS S.A.

- Cieza, J. (2016) Personas, Negocio Jurídico, y Responsabilidad Civil. Lima: Jurista Editores. Chaname, R. (2009) Comentarios a la Constitución. Lima: Jurista Editores.

- Espinoza, J. (2014) Derecho de las Personas. Concebido -Personas Naturales. Lima: Editorial Rhodas.

- Fernández Sessarego, Carlos (1984) La Persona en la Doctrina Jurídica Contemporánea. Lima: Fondo Editorial de la Universidad de Lima. 
- Fernández Sessarego, Carlos (1990) Nuevas Tendencias en el Derecho de las Personas. Lima: Fondo Editorial de la Universidad de Lima.

- Fernández Sessarego, Carlos (2000) Derecho de las Personas. Lima: GRIJLEY.

- Fernández Sessarego, C. (2009) Los 25 años del Código Civil Peruano de 1984.Lima: Motivensa

- García V. (1998) Análisis Sistemático de la Constitución Peruana de 1993. Tomo I. Lima: Fondo de Desarrollo Editorial de la Universidad de Lima.

- Guevara. V (2004) Personas Naturales. Lima: Gaceta Jurídica.

- Guevara. V (2018) El Derecho a la Información frente al Derecho a la Intimidad. Lima: Universidad Femenina del Sagrado Corazón.

- Mesinas, F. (2010) Jurisprudencia civil y procesal civil de carácter constitucional. Lima: Gaceta Jurídica.

- Morales, J. (2009) Instituciones del Derecho Civil. Lima: Palestra Editores.

- Nery N. (2019) Cesión de Derechos de Imagen en Congreso Internacional de Derecho Civil. Tomo I. Lima: Instituto Pacifico - Universidad de Lima.

- Rescigno, P.(1986) Comentarios al Libro de Derecho de las Personas del Nuevo Código Civil Peruano de 1984 en El Código Civil Peruano y el Sistema Jurídico Latinoamericano. Lima: Cultural Cuzco.

- Rubio, M. (2008) Para Leer la Constitución de 1993. Lima: Fondo Editorial de la Pontificia Universidad Católica del Perú.

- Rubio. M. (1992) El Ser Humano como Persona Natural. Biblioteca para Leer el Código Civil. Vol. XII. Lima: Fondo Editorial de la Pontificia Universidad Católica del Perú.

- Valencia Zea, A y Álvaro Ortiz (2008) Derecho Civil. Tomo I. Parte General y Personas. Bogotá: Temis.

- Varsi, E. (2014) Tratado de Derecho de las Personas. Lima: Gaceta Jurídica.

Fecha de recepción: 22 de mayo de 2020

Fecha de aceptación: 01 de junio de 2020 